\title{
Effect of Magnetizing the Fuel on the Performance of an S.I. Engine
}

\author{
Dr. A. R. A. Habbo \\ Raad A. Khalil \\ Hassan S. Hammoodi \\ University of Mosul, College of engineering, Mechanical Engineering Department, Mosul .
}

\begin{abstract}
The aim of this study is to investigate the effect of the magnetized fuel on the performance of spark ignition engine. The engine performance was observed by examining the engine brake power (BP), thermal efficiency, specific fuel consumption (SFC) and exhaust emissions.The fuel is subjected to a magnetic field which is placed to fuel supply line to magnetize the fuel before admitted to the engine cylinder. Two types of magnetic coils were adopted in this study, the first one with 1000 Gauss and the second with 2000 Gauss. Experimental tests were conducted at a speed of $2000 \mathrm{rpm}$, compression ratio 8 , wide open throttle (WOT) and ignition timing was set between $5^{\circ}$ and $30^{\circ}$ BTDC. The results show a significant improvements in engine performance, the thermal efficiency and engine power increased by (4 $\%)$ and $(3.3 \%)$ respectively when a magnetic coil of 1000 Gauss is used, and a reduction in the specific fuel consumption by $(\mathbf{1 2 . 8} \%)$ was achieved. However, when the magnetic coil of 2000 Gauss is used the brake power is increased nearly by $(16.4 \%)$, thermal efficiency showed an improvement nearly by $(7.6 \%)$, while the specific fuel consumption is decreased by $(21.3 \%)$ with respect with no magnetic field case. The exhaust gas emissions show a reduction nearly by (80\%) of $\mathrm{CO}$ and by (44\%) of $\mathrm{HC}$ when the magnetic coil of 1000 Gauss is used. A further reduction nearly by $(90 \%)$ of $\mathrm{CO}$ and by $(58 \%)$ of $\mathrm{HC}$ is obtained when the magnetic coil of 2000 Gauss is used .
\end{abstract}

$$
\begin{aligned}
& \text { تأثير مغنطة الوقود في أداء محرث احتراق داخلي بعمل بالشرر }
\end{aligned}
$$

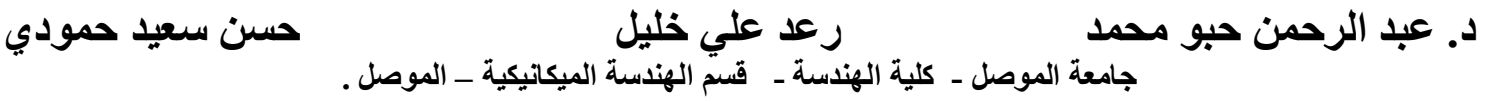

$$
\begin{aligned}
& \text { المستخلص }
\end{aligned}
$$

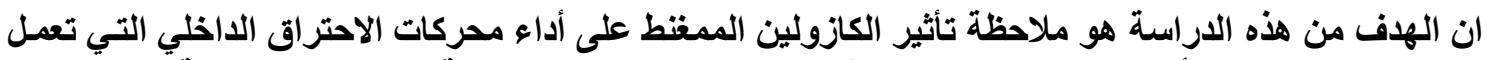

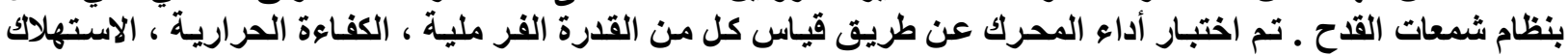

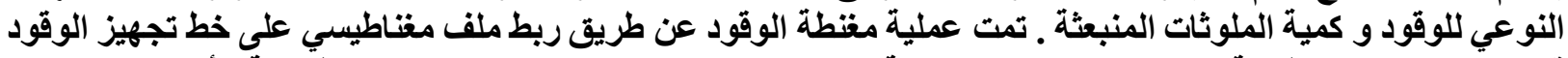

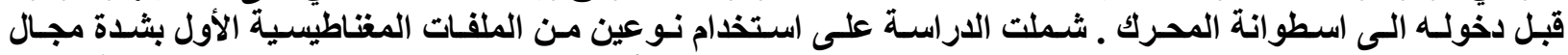

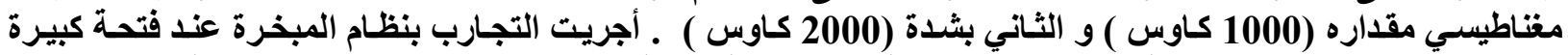

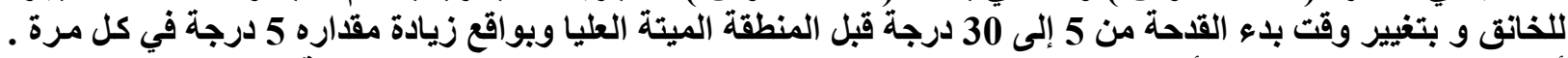

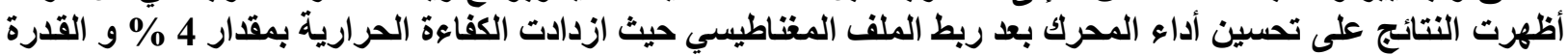

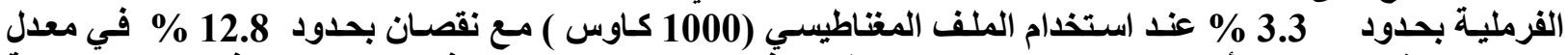

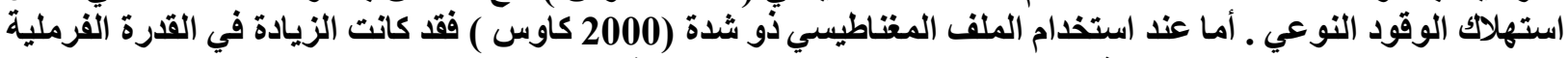

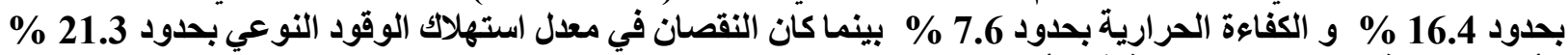

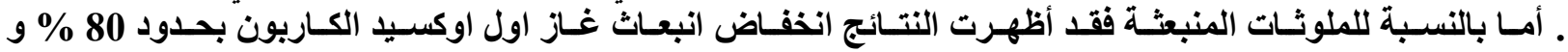

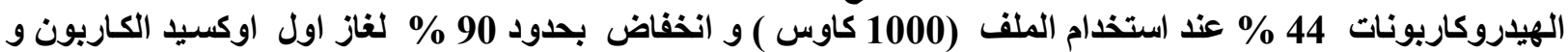

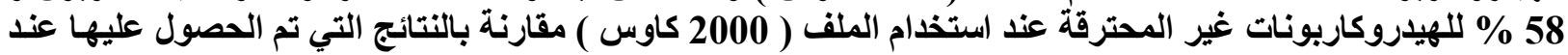

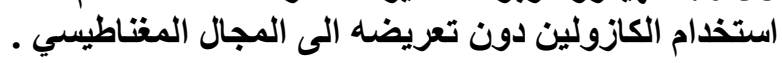




\section{Introduction:}

Internal combustion engines represent the main sector of hydrocarbon fuel consumption. On the other hand, as the fuel prices have increased sharply in the past few years due to high demand which reached up to $\$ 80$ per a barrel, therefore, engineers and researchers are now interested in improving engines performance ( increasing power output and reducing fuel consumption) in addition to reducing exhaust emissions . Researchers carried studies on using alcohols as a suitable alternative fuels because they are made from renewable sources , such as various grown crops and even waste products .

Hsieh, Chen, $\mathrm{Wu}$ and Lin ,[1] investigated experimentally the engine performance and emission of a spark ignition engine using ethanol-gasoline blend fuels in ratios of 5\%,10\%, $20 \%$ and $30 \%$. The results showed that with increasing the ethanol rate, the heating value of the blended fuels increased. They found that using the ethanol-gasoline blended fuels the engine torque and specific fuel consumption slightly increased .Abdel-Rahman and Osman [2] conducted performance tests on a variable compression ratio engine using different percentages of ethanol in gasoline up to $40 \%$. They found that the best compression ratio are 10,11 and 12 for $20 \%, 30 \%$, and $40 \%$ ethanol to give maximum indicated power respectively .Al-Baghdadi [3] investigated the performance of a spark ignition engine using hydrogen and ethanol as supplementary fuels . In their experiments, addition 8 mass $\%$ of hydrogen and $30 \mathrm{vol} \%$ of ethanol into the gasoline resulted in 58.8\% reduction in specific fuel consumption. In addition the power output and engine thermal efficiency increased by $4.72 \%$ and $10.1 \%$ respectively.

Koenig, Lee and Bernhardt [4], studied the technical and economical aspects of methanol as automotive fuel . From their results conducted on a single cylinder engine and using methanolgasoline blend as alternative fuel for motor vehicles, they found that such a mixture improved energy utilization, increased engine output, and improved knock resistance .

Huanran and Rui [5] found that by mixing 5-30 vol.\% of pure methanol with commercial gasoline and treating the mixture in an electrical field at $6-35 \mathrm{~V}$ and $0.1-30 \mathrm{MHz}$ for $10-50 \mathrm{~min}$., the mixed fuel is superior in combustion efficiency at low $\mathrm{NO}_{\mathrm{x}}$ emission.

Govendasamy and Dhandapani [6] studied the effect of using magnetic field on reduction of $\mathrm{NO}_{\mathrm{x}}$ emission in Bio-diesel engine with exhaust gas recirculation. They found that with the presence the magnetic field the brake efficiency increased by $5 \%$ and the values of $\mathrm{CO}$ and $\mathrm{HC}$ got reduced.

Janezak and Krensel [7] conducted an experimental test for magnetic power for treating fuel lines for more efficient combustion and less pollution. Their invention relates to the control of combustion and pollution by means of magnetic field processing of fuel lines at pre-combustion sites .

In the present study, two magnetic coils with different intensities were used to magnetize the fuel before entering the engine carburetor of a variable compression , single cylinder , 4stroke cycle , water cooled, electrically loaded spark ignition engine [ type TD 43] as shown in figure (1) . The study concentrates on engine performance by examining the brake power, fuel consumption, brake thermal efficiency and exhaust emissions .

\section{Experimental Work:}

A single cylinder, four - stroke cycle, variable compression ratio spark ignition engine is used in the present study. Its compression ratio is adjusted to be $8: 1$, and engine speed was set for $2000 \mathrm{rpm}$. The engine running at wide open throttle (WOT) at an equivalence ratio of $\Phi=1.0$ , and ignition timing was varied from $5^{0}$ to $30^{\circ} \mathrm{BTDC}$ at a step of $5^{0}$ each time . The fuel type 
used was a leaded gasoline which is available at local fuel stations which is produced by Northern Oil Company ( Beiji refinery ) .

Engine performance including brake power, brake specific fuel consumption and thermal efficiency are studied using leaded gasoline with magnetic effect, and without magnetic effects . Two types of magnetic coils were used to magnetize the fuel before entering the engine cylinder. This was done with aid of electric magnetic coil which is placed on the pathway of fuel, approximately at one meter before the carburetor system ,to ensure that magnetizing takes place . One of the coil with intensity of 1000 Gauss and the second with 2000 Gauss as shown by the schematic diagram of engine given in figure (2).

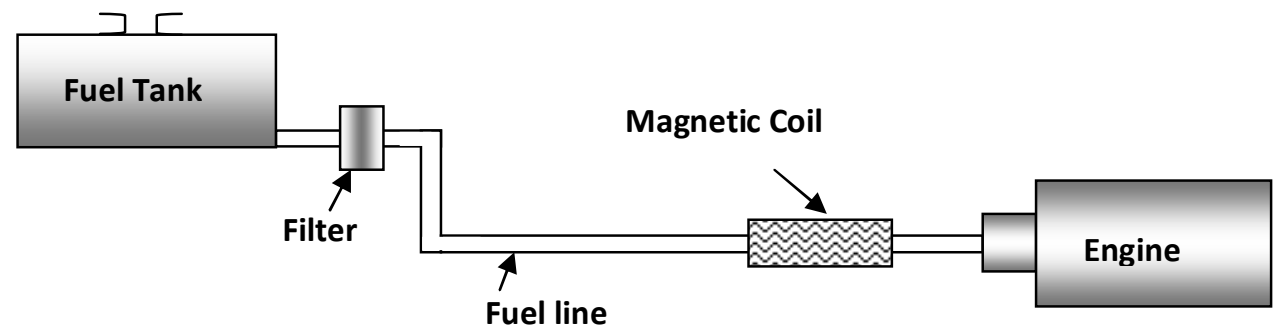

Figure 1. Schematic diagram for magnetic coil installation .

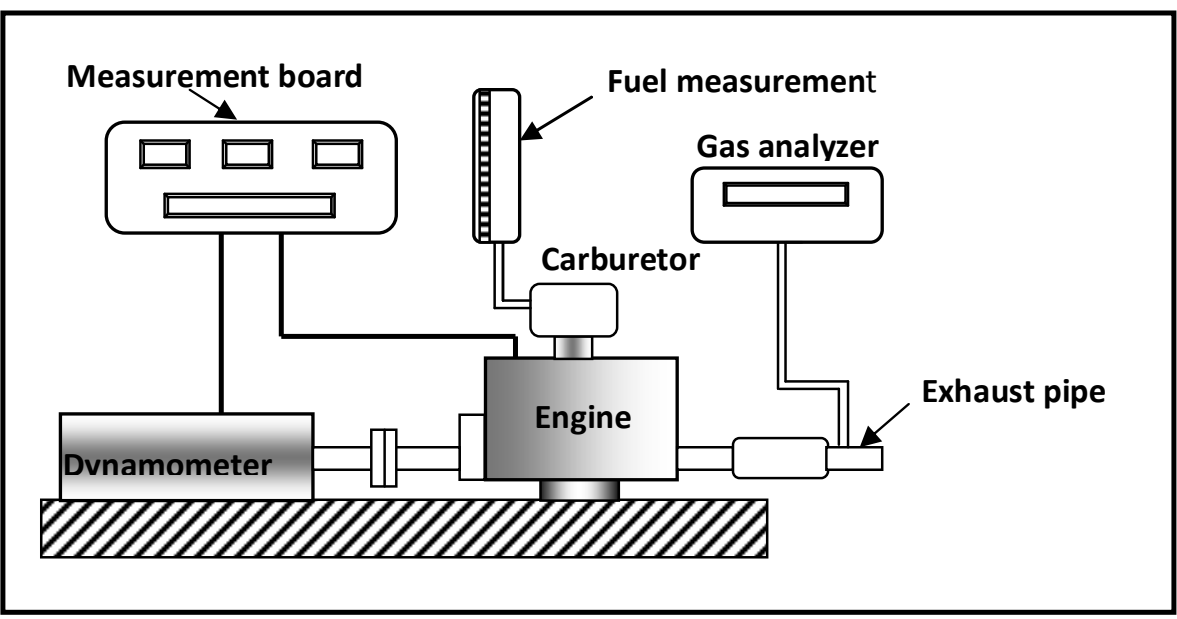

Figure 2 . Schematic diagram of engine test bed

\section{Results and Discussion:}

Spark ignition engine performance and its emission were studied using leaded gasoline fuel when magnetic field is used. Figure ( 3 ) shows the relationship between brake power and ignition timing for three different tests, without applying magnetic field, with magnetic coil of intensity of 1000 Gauss and finally with magnetic field of 2000 Gauss . The maximum brake power was found to be at $20^{\circ}$ BTDC for both coils. The percentage of brake power improvement was found to be $(3.3 \%)$ and $(16.4 \%)$ when magnetic coils (1000) and (2000) Gauss are used respectively. 


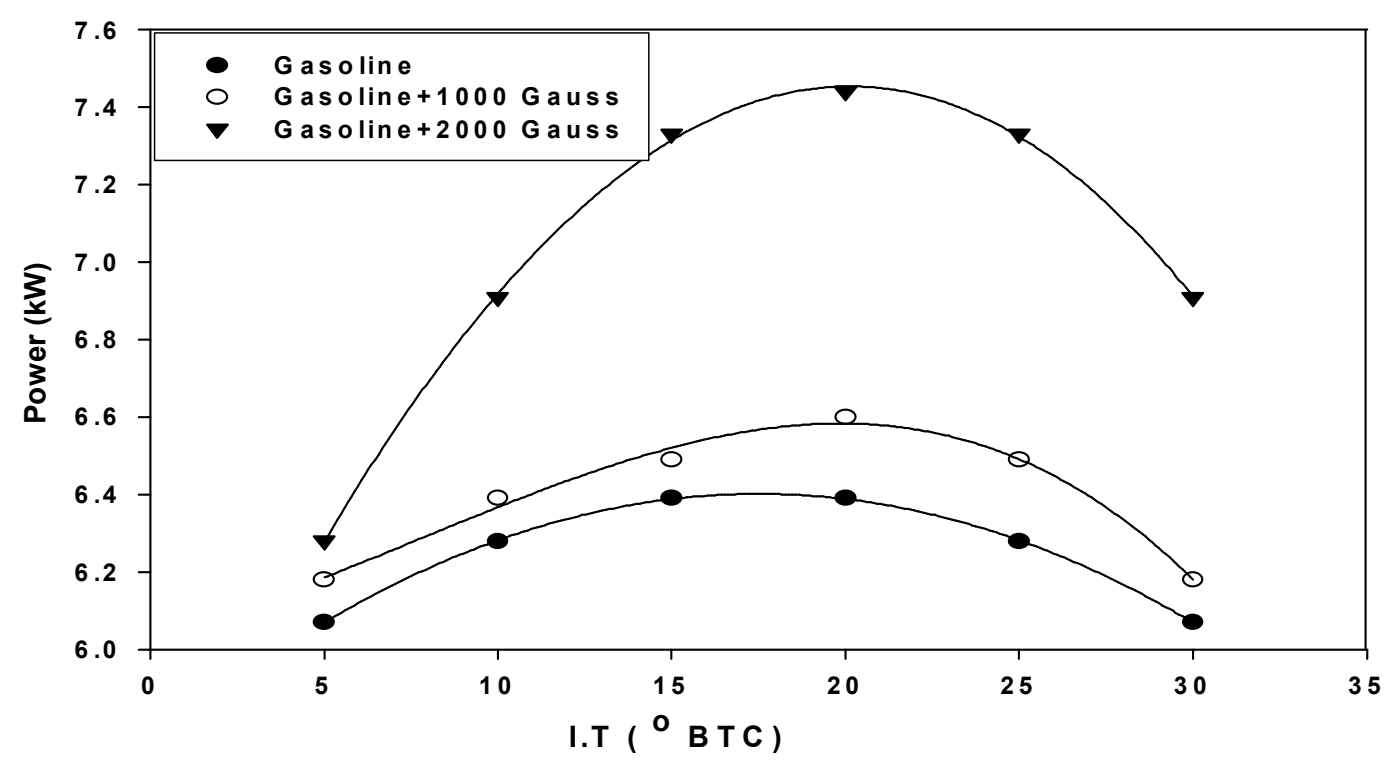

Figure 3. Variation of brake power with ignition timing

Figure (4) shows the relationship between specific fuel consumption and ignition timing at engine speed of $2000 \mathrm{rpm}$ and compression ratio of 8 . It can be seen that the specific fuel consumption is decreased nearly by (12.8\%) when a magnetic coil of 1000 Gauss is used; however, this reduction was measured to be approximately by $(21.3 \%)$ when a magnetic coil of 2000 Gauss is used.

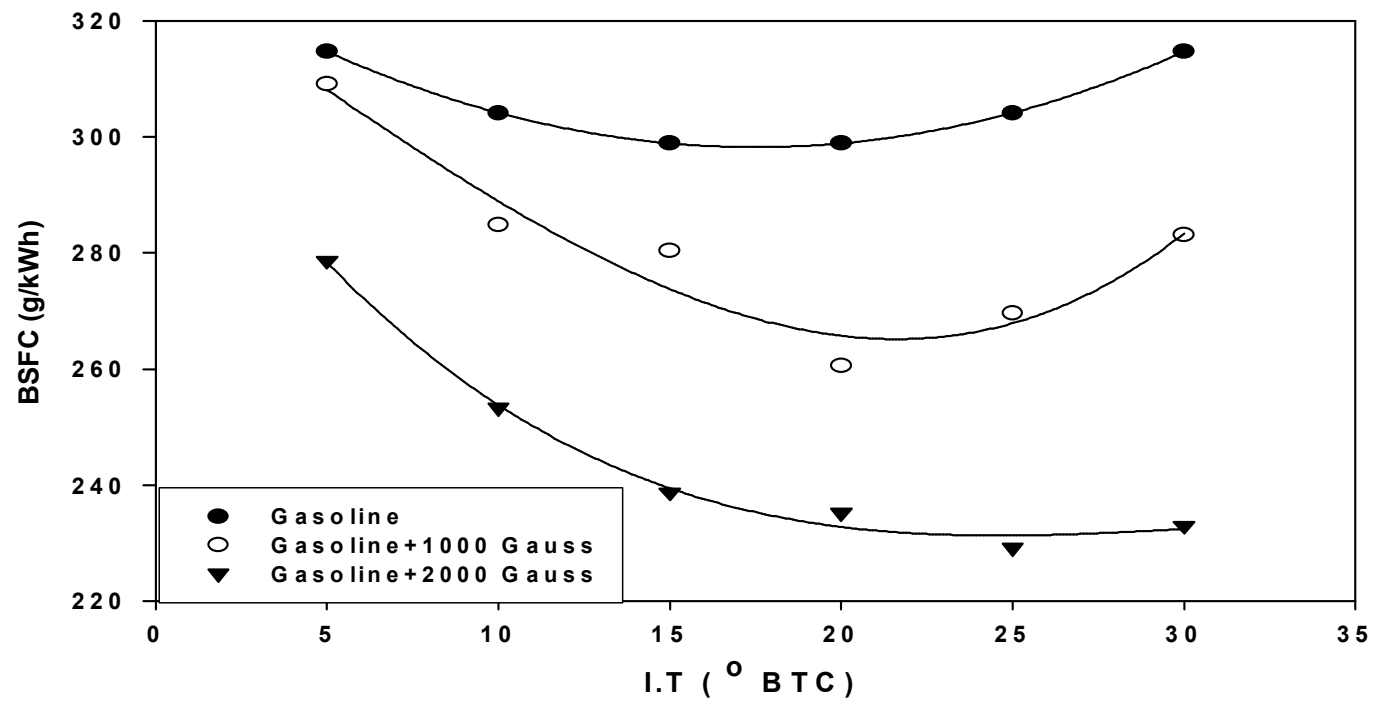

Figure 4. Variation of BSFC with ignition tim ing

The thermal efficiency also showed a good improvement when a magnetic coil is applied, results given in figure $(5)$, indicates that the thermal efficiency increased nearly by $(4 \%)$ and (7.6\%) for coil 1000 Gauss and 2000 Gauss respectively .

Moreover, the exhaust gases temperature also show a good improvements. Figure (6) shows the relationship between exhaust gas temperature and ignition timing for the same engine operating 
conditions ( $\mathrm{r}=8, \mathrm{sp}=2000 \mathrm{rpm}, \Phi=1.0$ ) for all cases . Results indicate that exhaust gas temperature decrease nearly by $(5.7 \%)$ and $(8.6 \%)$ for coils 1000 and 2000 Gauss respectively.

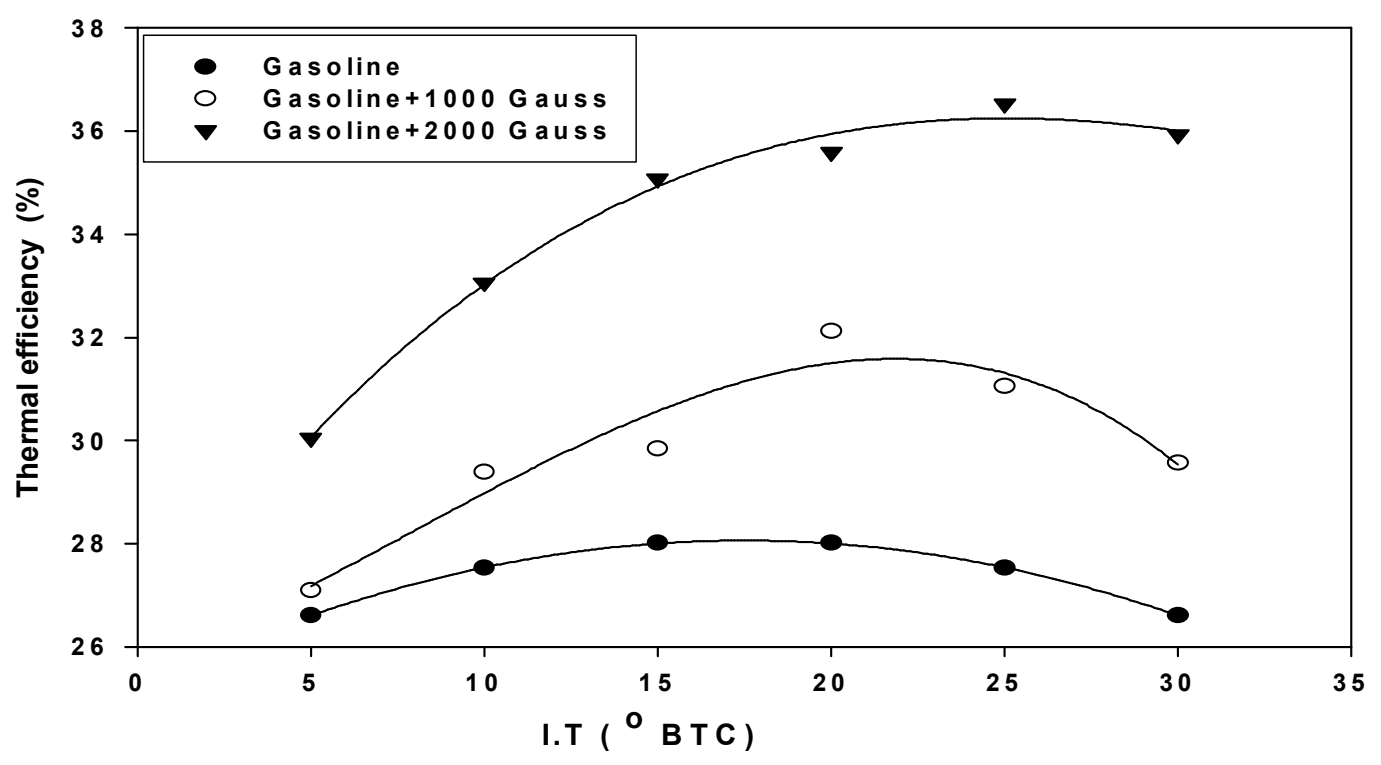

Figure 5. Variation of thermal efficiency with ignition tim ing

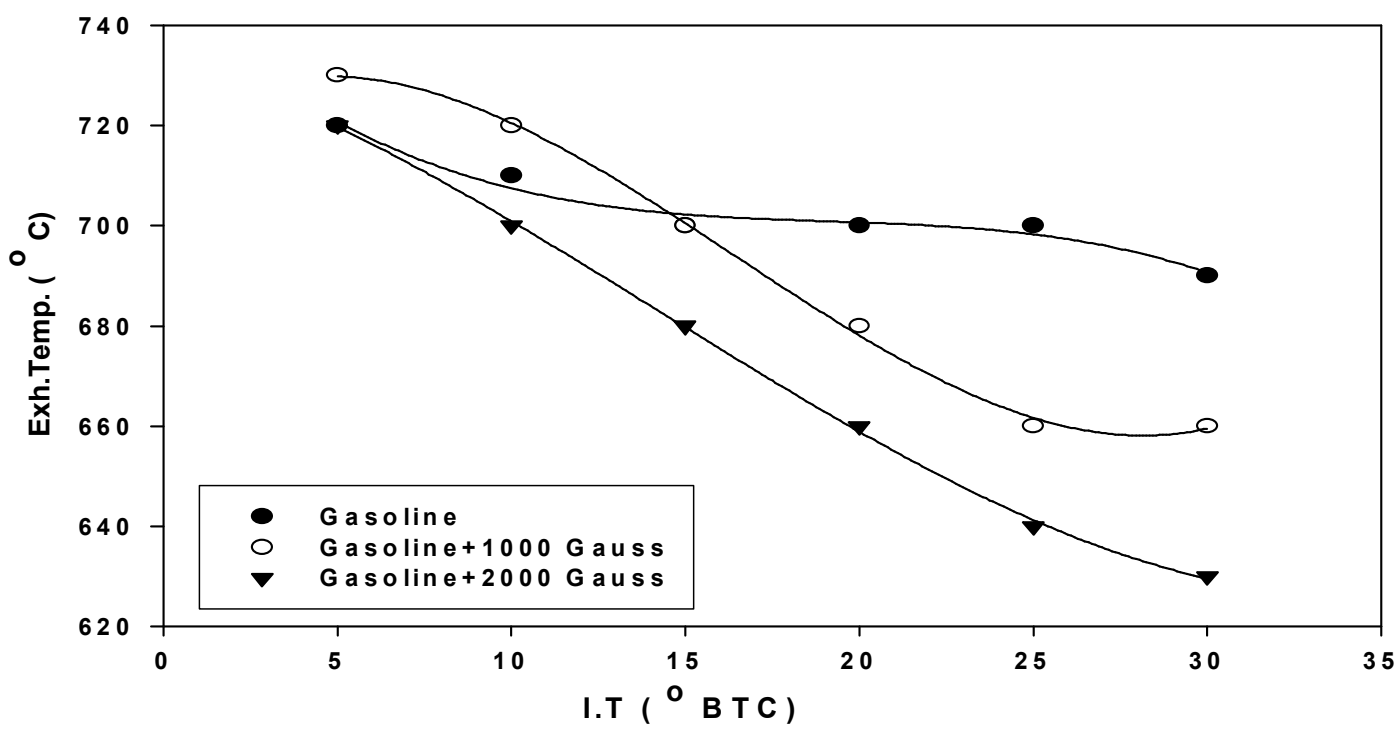

Figure 6. Variation of exhaust gas temperature with ignition timing

Finally, implementing a magnetic field on the pathway of engine fuel was found to have a significant influence on the amount of emission. Results show that both carbon monoxide (CO) and hydrocarbon (HC) emissions have been reduced. Figure (7) shows that hydrocarbon is decreased nearly by (45\%) and (58\%) when magnetic coils 1000 and 2000 Gauss are used respectively. Figure (8) shows that carbon monoxide emission is reduced nearly by $(80 \%)$ and $(90 \%)$ for both coils respectively. 


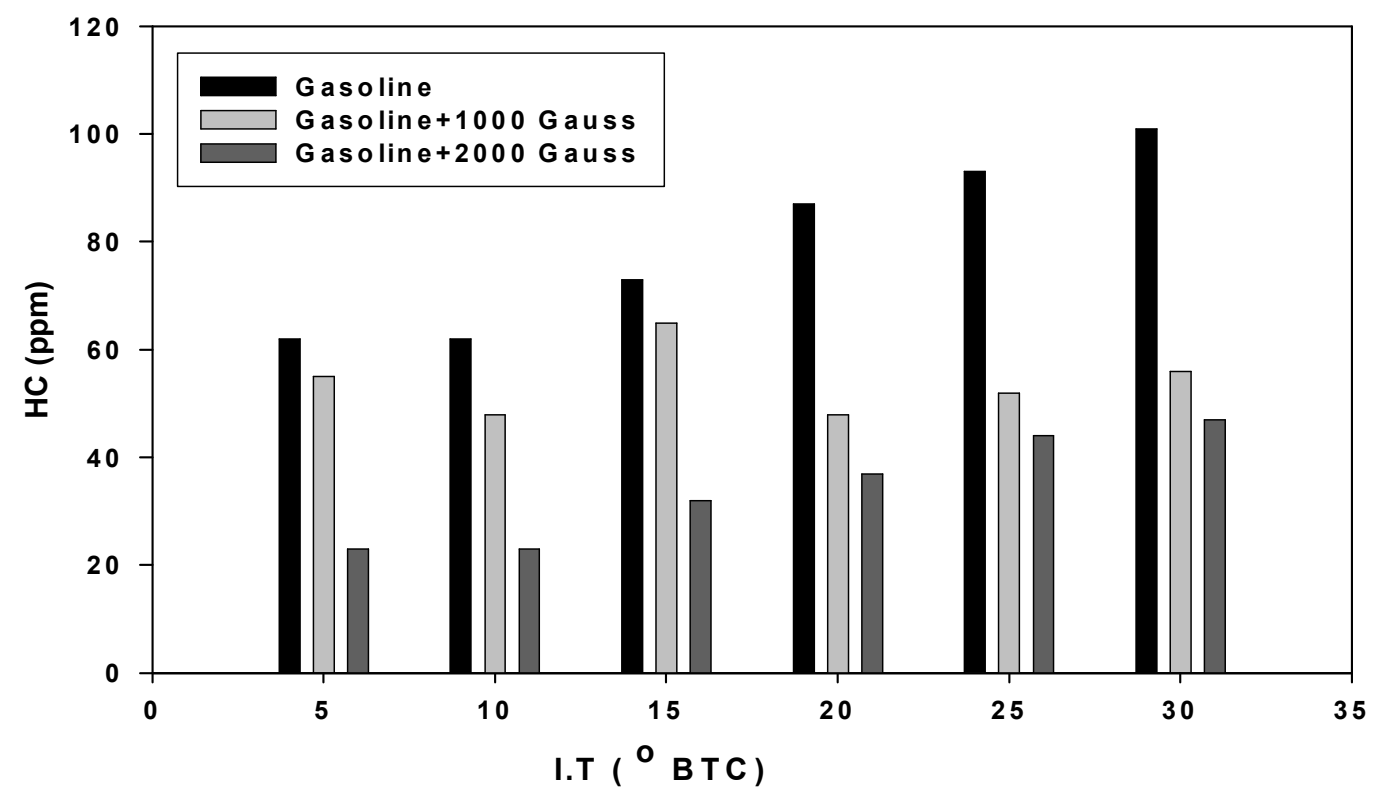

Figure 7. Variation of HC with ignition timing

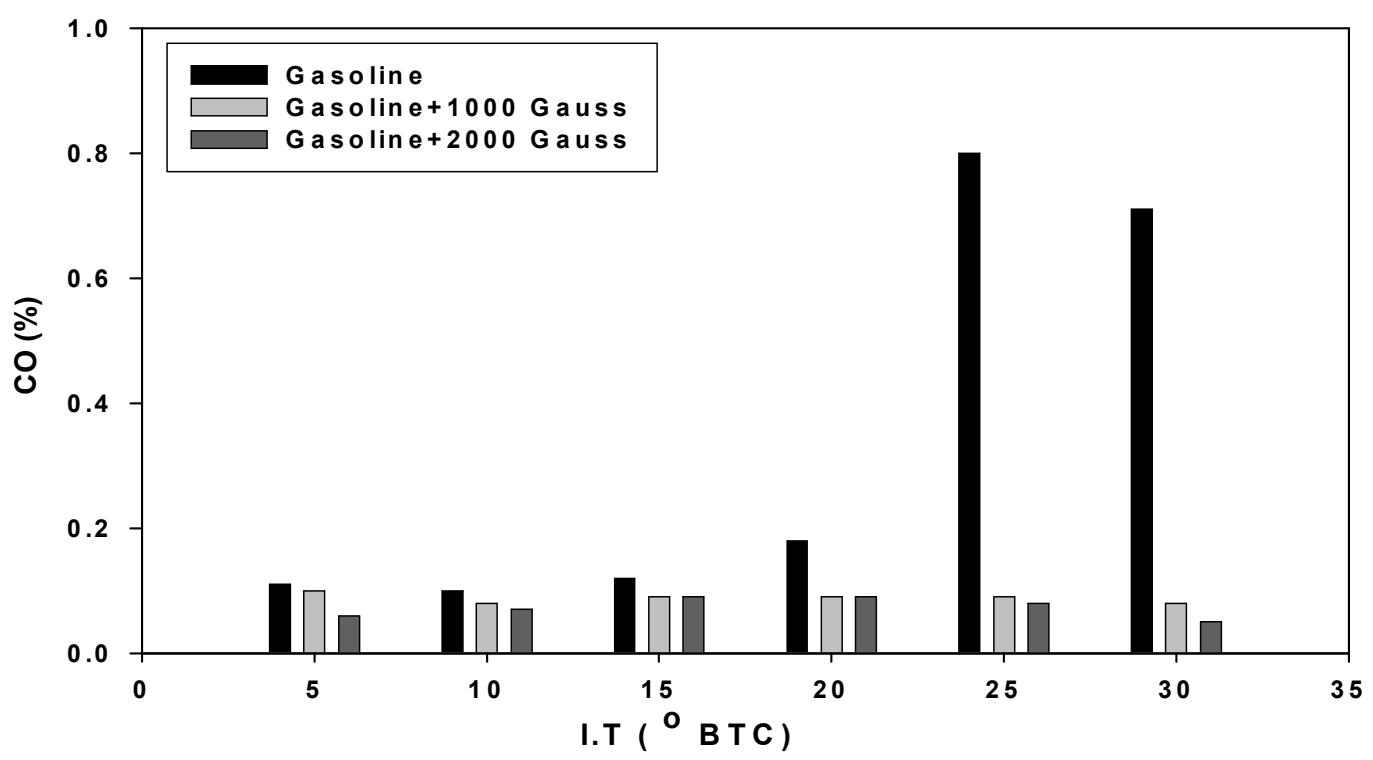

Figure 8. Variation of $\mathrm{CO}$ with ignition tim ing

\section{Conclusions:}

From the experimental results that have been obtained in the present study for spark ignition engine performance running on leaded gasoline with and without subjected to magnetic field; the following conclusion can be stated and as follows : 
1- Results show that brake power increased due to placing magnetic coil before the engine carburetor to magnetize the gasoline fuel before entering the engine cylinder. It is also found that the power increases as the intensity of magnetic field increases too.

2- With regard to the specific fuel consumption, it be seen that the magnetic field has positive effect on it. This means that specific fuel consumption decreases as the magnetic field intensity increases.

3- The thermal efficiency was improved relatively with the magnetic field intensity.

4- Focusing on emission, it was found that $\mathrm{CO}$ and $\mathrm{HC}$ emission decrease due to using of magnetic field to magnetize the fuel before admitting to the engine cylinder .

5- Finally, it can be concluded that using magnetic field with high intensity has a positive effect on spark ignition engine performance and emission.

\section{References :}

[1] W. D. Hsieh, R. H. Chen, T. L. Wu and T. H. Lin . Engineering performance and pollutants emission of an S.I. engine using ethanol-gasoline blended fuels . Atmospheric Environment Journal, vol. 36 (3) 2002, pp.403-410.

[2] A. A. Abdel-Rahman and M. M. Osman . Experimental investigation on varying the compression ratio of S.I. engine working under different ethanol-gasoline fuel blends . International Journal of Energy Research 21(1) , 1997 , pp. 31-40 .

[3] M. A. S. Al-Baghdadi . Performance study of a Four-stroke ignition engine working with both of hydrogen and ethyl alcohol as supplementary fuel . International Journal of Hydrogen Energy , 25 (10) , 2000 , pp. 1005-1009 .

[4] Koenig, A. , Lee, W. and Bernhardt,W. Technical and economical aspects of methanol as an automotive fuel. SAE Technical paper No. 760545, 2006 .

[5] Huanran , H. and Rui , Z. . Methanol- gasoline mixed fuel for gasoline engine , Patent number $20010704,2001$.

[6] P. Govndasamy , S. Dhandapani . Reduction of $\mathrm{NO}_{x}$ Emission in Bio Diesel Engine with Exhaust Gas Recirculation and Magnetic Fuel conditioning .International Conference on Sustainable Development, challenges and opportunities for GMs 12-14 Dec. 2007.

[7] A. Janezak , E. Krensel . Permanent Magnetic Power for treating fuel lines for more efficient combustion and less pollution .U.S. Pat. 5,124,045,1992.

The work was carried out at the college of Engineering. University of Mosul 